\title{
APPLICATION OF NEURO-LINGUISTIC PROGRAMMING TECHNIQUES TO ENHANCE THE MOTIVATION OF AT-RISK STUDENT
}

\author{
Sabariah Sharif ${ }^{1}$, and Emila Rohaza Abdul Aziz ${ }^{2}$ * \\ ${ }^{1}$ Universiti Malaysia Sabah, Malaysia, edpss@hotmail.com \\ ${ }^{2}$ Ministry of Education, Malaysia, emilarohaza@gmail.com \\ * Corresponding Author
}

\begin{abstract}
Motivation is the trigger of an individual behavior to achieve an outcome. Despite motivation, there are values and beliefs that affected by the mind. By seeing the concept of mind as the controller of a person's behavior, this study has been carried out using Neuro-Linguistic Programming (NLP) as the intervention to increase the motivation of at-risk students in the prison. Intrinsic motivation in this study area consists of selfconfidence, intention to change, interest to study and perspective to life after release from the jail. Pre and post experiment with qualitative approach by using interviews and observation to six students had been done. There are three main interventions from NLP that being used in this study that are Progressive Relaxation Technique, Discover Your True Values Technique and Circle of Excellence Technique. These three techniques had been carried out one by one and the data is related. All the data has been transcribed and analyzed to answer three main questions of this study. This study shows that application of NLP techniques increases the motivation of high risk students effectively. Overall, this study has been success to enhance the motivation among at-risk students in the prison and hopefully can be used to increase the quality of human resource produced through education.
\end{abstract}

Keywords: Neuro-Linguistic Programmings, at-risk student

\section{INTRODUCTION}

Method of teaching in schools was initiated by a variety of theories and concepts that have been performed for centuries. The variety of teaching approaches used only to ensure effective learning takes place. Effective learning is said to occur when there is a change in behavior that is shown in the attitudes of students. From previous studies, effective learning takes place only if the student is in a state that ready to accept the teaching taught by the teacher. In other words, students are in a state of readiness and motivated to learn. In addition, the motivation is also a desire for the best results and the factors that contribute to the process of learning (Stipek et al. 1998)

Motivation is an important element in life. Motivation refers to the reason for the attitude of willingness and desire (Lai, 2011). Motivation drives like a moving body and soul of an individual to achieve the expected aim. What about the relationship with student motivation? Students who are motivated will always have a higher requirement to learn and achieve success in life. Internal or intrinsic motivation is one element that often drives the success of students in academic and extra-curricular. This statement is supported by Deci et al.(1999) which states that intrinsic motivation is needed for effective learning more than external motivation. On the other hand, students who are at-risk or troubled in schools typically have low motivation and unsure of the direction of life. Therefore, they are easily influenced by social and involved in crime.

Among the factors, which led to social ills among students include environmental factors such as family 
background, peer pressure, the influence of mass media as well as internal factors the students themselves who have problems of identity ambiguity. This statement is supported by studies of Bernes (1992) which states that if nothing is done to control for teens, this will cause them to feel isolated, low self-esteem and can lead to more aggressive behavior. Unhealthy environmental conditions can also cause students to be influenced by a variety of criminal offenses.

In addition, young students who violate the norms of the local community or in the school institution is categorized as deviant and deliquent behavior. They are not just naughty with cigarette smoking, truancy, fighting teachers, vandalism, fighting with each other, but also to be involved in misconduct more remarkable as to the gangs or gangsters, running away from home, free sex, abandoned babies and more (Badrulzaman, 2006). Therefore, those who have made a criminal offense and getting caught by the authorities will be imprisoned and sentenced accordingly. Students who drop out of the academic aspect are the students that are the focus of this research. At-risk students of been selected for this study was composed of students who are serving prison sentences for various offenses. They are also students at the Integrity School in prison, which the school system is the same as regular national secondary school.

By taking into account the characteristics, attitudes and low motivation among at-risk students, an application of new knowledge was used in this study. The interventions used in this study are Neuro-Linguistic Programming (NLP) technique, which aims to enhance the motivation among at-risk students. NLP is a systematic study of human behavior (Mat Taib, 2009). NLP also is an effective management tool to change how people think and act (Shapiro, 2012). NLP has been around since the early 1970 s and has been widely used in various fields such as communication, business, psychotherapy, personality development, education and counseling.

Moreover, NLP can increase the motivation of at-risk students because NLP is a communication technology (linguistic) that formed from the mind (neuro) are manipulated to produce a desired change (programming). In other words, NLP serves as a tool which will change the thinking of the next action towards a more positive approach in communication.

\section{MOTIVATION, NLP AND HIGH-RISK STUDENTS}

\subsection{Motivation}

Motivation can be defined as the attitudes of students, including the willingness, need, desire to participate to be successful in the learning process (Bomia et al . 1997). Motivation in this study is more to intrinsic motivation (internal) which is motivation that drives and maintains spontaneous satisfaction in line with the will and action and it is reflected in behaviors such as play, exploration and challenge leading to external rewards (Deci et al ., 1999 ). In this study, the focus of intrinsic motivation is the internal motivation of at-risk students such as self-esteem, desire to change, and passion for learning and positive perspective on life after independent.

Motivation refers to the reasons behind the behavior exhibited by an individual (Guay et al., 2010). Motivation is defined as the effort to move an individual to do or not to do something (Gredler et al., 2004). Motivation involves the integration of beliefs, perceptions, values, interests and actions interlocking to each other (Lai , 2011). As a result of this integration, diversity in approach motivation will focus on cognitive behavior.

For example, studies Gottfried (1990) defines motivation as academic learning at school fun featuring mastery learning orientation, the desire to know, persistence, challenge and difficulty learning new tasks. In addition, the motivation may have the same meaning to the cognitive abilities that can be defined as a voluntary gesture to achieve higher levels of learning strategies such as concentrating, correlating, planning and monitoring (Turner, 1995).

In conclusion, the definition of motivation can be described as a plan or desire to strive for success and avoid failure in life. In other words, motivation is the process of producing energy by the direct needs of the achievement of a goal. A person who has the motivation means the individual has acquired the strength to achieve excellence and success in life. With this motivation, then see cooperation, tendencies of helping each other and strive for success.

\subsection{Neuro-Linguistic Programming (NLP)}

Neuro-Linguistic Programming (NLP) is the psychology of excellence (Bashir, 2012) and is also a process that can be applied to a model of excellence in various fields (Walter \& Bayat, 2003). NLP can be used as a technique for a doctor talk with patients, the technique of a teacher to communicate with students, the 
technique of a lawyer or a police officer talking to witnesses, a technique of politicians to influence subordinated and other various applications. In this study, NLP is used as the application to increase the motivation of high-risk student.

Neuro-Linguistic Programming is a combination of three words, namely Neuro, Linguistic and Programming. According to Bailey (2001), the word neuro is derived from the Greek word neuron which means the nerves of the brain and in NLP, neuro refers to the notion that all individual behavior is due to neurological processes in the brain. Linguistic is derived from the Latin word lingua meaning language. In NLP, linguistic is based upon the principles of neurological processes is directed, organized and formulated the dynamics within an individual, then it will be translated through the language of communication. The programming refers to the process used in the sense of organizing or reorganization of an individual to achieve a particular goal. Programming attitude also produces the so-called strategy.

In other words, NLP seems like a program organized by the brain to produce what is expected and it is translated through communication. Thus, NLP can also be a tool to influence the mind to make changes. As a benefit, NLP allows an individual to substitute behaviors and negative attitudes to more positive to achieve success. Thus, NLP is also known as software of the brain or brain software to achieve excellence.

\subsection{At-risk student}

At-risk student is defined as a regular student at the school who is at risk to fail or are unable to succeed in school due to various factors and all students are considered at risk of a negative impact on their self, family and country (Wan et al., 2009). In this study, at-risk students chosen are Integrity School students who are prisoners under 21 years who have been convicted of a criminal offense and is serving a sentence in a criminal offense, respectively.

According to Wan et al. (2009), the question of the meaning of 'at-risk' remains a controversy. When a student is not successful in his studies, teachers, parents and community mutual recrimination, who and what the cause was. Whatever the reason, this problem is very important to be noted, because the costs are caused by the society and the country either economically or socially for the underachievement (underachievers) higher. The situation became more critical when every year the number of students who enter school with an 'at-risk' on the rise because the school cannot meet their needs.

According to the Educational Resources Information Center (1987), the word used to refer to the risk of academic failure and failure at school, potential dropouts, no education, and underachievement. ERIC definitions have in common with the views Liontos (1992), which states that students who are at-risk students are at risk of school failure. Next American Arts Organization (AAO) defines a child as a child at-risk of exposure to a variety of factors that cause them to engage in problem behavior as criminal or criminals. They are stuck with a crime under the age of 18 and was convicted by the court of children, their own children classified as at-risk. In terms of legislation, there are many other definitions of children at-risk as defined in the Washington Family Reconciliation Act, and the Colorado Youth Mentoring Services Act.

However, Pallas (1994) argues that no single definition really shows that the occurrence of children at-risk. Due to Pallas, school is not the only educational institution. Family, community and school education is the key. Therefore, Pallas defined children at-risk or lack of education is that they are exposed to educational experience inadequate or inappropriate, whether family, school or community. However, the meaning of educational experience is not enough or the right because the experience is different from one individual to another individual. However, his views were given the guidance on how to assess a child as belonging to the risk group.

Based on some of the terms above, there are various definitions of at-risk students. But clearly, all students who are considered at-risk had a negative impact on themselves, their family and the country. For the purpose of this study, at-risk student is focused on learning of school children, students at-risk is defined as the average student in school who are at-risk to fail or are unable to succeed in school due to various factors. According to a study published by The Solon Community School District. At-Risk Plan of Services (2003) these factors can be identified by the criteria in three categories at-risk students, the students who do not reach goals in education, students who do not participate because of social or emotional problems, and students who are not expected to be a productive employee.

Within the scope of this study, students at-risk is defined as a student under the age of under 21 years old who have been convicted of a criminal offense under the law of the court and is serving a sentence in prison. They also hold the status of prisoners when release in the future where they do not qualify to do work with government sectors. However, they still had the opportunity to work in the private sector or self-employed. 
Based on the concept of Education for All, then this at-risk students still have the opportunity to continue their education at the Integrity School in prison.

\section{METHODOLOGY}

This study is a case study and using qualitative interview techniques as well as pre-and post- observation in the treatment group of Neuro-Linguistic Programming (NLP) techniques. The study chose only 6 respondents that researchers would like to investigate in depth of the effects of NLP techniques increase the students' motivation. In addition, three types of triangulation are performed to obtain the validity of the data witches are triangulation time, sources and methods. However, the study is focused more on the use of NLP techniques to enhance students' motivation.

In this study, there are three main NLP technique is used as an intervention which are Progressive Relaxation Technique, Discover Your True Values Technique and Circle of Excellence Technique. All three interventions are carried out in sequence on the same day. However, the pre-interview conducted the day before the intervention and post-interview conducted the day after the intervention to ensure the informants really responded symbolize the effectiveness of NLP techniques used during interventions conducted. During the pre and post run interview, the researcher uses three other NLP techniques to get the most honest answers from the informants that are Building Rapport Techniques, Eyes Accessing Cue Technique and Meta Questioning.

The process of data analysis conducted after each interview and observation. This is to ensure that researchers do not miss any part of the scope of the study were to investigate. The researcher conducted interviews and observations repetition when there are elements that are not to be unlocked in the first interview. Therefore, the analysis after each data collection is very important and will affect the findings.

Table 1 Intervention Methodology

\begin{tabular}{|l|l|l|}
\hline Research Procedure & Instrument & NLP Techniques \\
\hline FirstTime Data Collection & Pre-Interview & $\begin{array}{l}\text { 1) Building Rapport } \\
\text { 2) Eye accessing Cue } \\
\text { 3) Meta Questioning }\end{array}$ \\
\hline Intervention & Treatment of NLP & 1) Building Rapport \\
& techniques & $\begin{array}{l}\text { 2) Progressive Relaxation } \\
\text { 3) Discover Your True }\end{array}$ \\
& & Values \\
\hline Second Time Data & Post- Interviews & 1) Bircle of Excellence \\
Collection & & 2) Eye accessing Cue \\
& & 3) Meta Questioning \\
\hline
\end{tabular}

\section{RESULTS}

In this study, the results obtains is in the form of video recordings and transcribed interview dialogue. The result of this study is divided into two types which are transcriptions of interviews and pre-and postobservation after treatment NLP interventions. The transcription detailed findings by pointing out eight key questions (main theme) to answer research questions. The interview is conducted unstructured interviews and in local Sabah Malay Language.

Researchers have classified the questions of pre and post interview in this study into three categories according to the research question. From the analysis of the overall findings of this research, three main research questions are also objectives of the study have been successfully answered. Moreover, an additional question related to the effectiveness of interventions Neuro-Linguistic Programming (NLP) has also been successfully answered.

Firstly, the study questions whether the application of Neuro-Linguistic Programming (NLP) is effective in increasing the intrinsic motivation of students at risk in terms of self-confidence and desire for change. To answer this question, researchers put forward three main questions, namely, whether the informant was feeling particularly school. The second question, the researchers asked whether the informants feel confident with them. For both of these questions, two of the six informants showed significant changes after the treatment of the informant's informants 1 and 6 . From the analysis of transcription and video observation, it was found that the informant 1 and 6 undergone significant changes after treatment due to low educational 
background and both were not undergoing formal learning at school. The four other informants do not show significant changes after treatment for having a high level of intrinsic motivation due to higher levels of schooling before entering the prison and the entry into prison longer. The third question is whether the informant is ready to change the attitudes and behaviors for the better life. To this question, all of the informants gave a positive answer that they are willing to change their attitudes after treatment.

The second question of this study is the application of Neuro -Linguistic Programming (NLP) is effective in increasing students' interest in the study. To answer this question, the researchers asked how the level of interest to learn if given the scale of 1 to 10. For this question, two showed significant interest after the treatment. The informant was the first informant and the sixth informant. Similar to the above, both informants had no interest in learning before treatment is carried out at a low level of education before. Thus, after treatment, their interest in learning has been successfully scaled up to a higher scale. However, the level of interest both informants are not at the maximum level which is 10. Therefore, the researchers expect some more treatment sessions should be conducted so that the level of interest they are at the highest level to enable them to cope with upcoming exams better.

Thirdly, the question of whether the application of Neuro-Linguistic Programming (NLP) techniques is effective in changing negative perceptions of students at risk of having an independent life. To answer this question, researchers present the first three questions, namely, how the views of informants against him after release from the jail. For this question, three informants showed a view of themselves positively after release that are informant 4,5 and informant 6 . For this question, the researchers analyzed the transcription and the observation of the three informants and find informants 4 and 6 do not feel confident with themselves because the sentence is too long. The informants 5 was a first timer commits a criminal offense and pleaded guilty to the charges and his cousin brother. Therefore, he felt that the external public opinion negative about him after release from the jail. After treatment, all three informants showed a positive change in themselves. As for the second question, whether the informant feel confident to face the outside world after the release show all informants feel more confident to face the outside world after treatment. The third question of whether they feel that they still have hope also showed all informants feel they still have hope in life after undergoing treatment.

Last but not least, the researchers asked whether the informants felt that the treatment is carried out effectively within them. For this question, all of the informants express the treatment were effective in which two informants answered very effectively especially informants 3 and 6 . Effectively, it is stated on their feelings after undergoing treatment where they feel there is a change in themselves.

Overall, the results show that the treatment carried out NLP intervention is effective in motivating students at risk in prison. Although all informants came from different backgrounds, but managed to find a treatment technique, NLP key value held by each informant and trigger enhancement of intrinsic motivation in each of the informants. Every student needs a different number of treatment sessions due to personal circumstances are different.

\section{CONCLUSION}

This study has proven the application of Neuro-Linguistic Programming (NLP) is effective in increasing the intrinsic motivation of high-risk students in prison. Intrinsic motivation is addressed in this study covers aspects of self-confidence, desire for change, a passion for learning and perspective on life after independent. The experimental study of pre-and post qualitative approach was performed by using interviews and pre-and post-treatment observation. Selected treatment is a technique derived from the application of NLP techniques consisting of Peace Progressive Techniques (Progressive Relaxation Technique), Exploring the Value of Your Real Techniques (Discover Your True Values Technique) and Technical Excellence Circle (Circle of Excellence Technique). All three techniques are carried out in sequence and findings related to each other. The result is expressed in terms of analysis and transcription were able to answer three main research questions.

It is hoped that these findings could have a positive impact, especially on the quality of work performed by teachers in schools. This is because the teacher is not just imparting knowledge, but also educates students from all areas outlined in the Malaysia National Education Philosophy. If this technique can be applied by all teachers to motivate students in the teaching and learning process in the classroom, it will be a real learning situation arises that is more comprehensive that is expected to produce students who are really knowledgeable and not measured based on exam performance alone. 


\section{REFERENCE LIST}

Asmawati Desa. Psikologi Untuk Golongan Profesional. Universiti Kebangsaan Malaysia: McGraw-Hill (Malaysia) Sdn. Bhd., 2002

B. Badrulzaman, Persekitaran Keluarga dan Kesannya Terhadap Tingkah Laku Devian Remaja di Daerah Pontian, Johor. Johor: Universiti Teknologi Malaysia. Thesis Sarjana. B. 2006.

R.Bailey,.NLP Counselling. Great Britain: Speechmark Publishing Ltd. 2001

A. Bandura,. Self-efficacy: The exercise of control. New York: Freeman. 1997

A. Bashir, A., \& M. Ghani,. Effective Communication and Neurolinguistic Programming. Pak. J. Commer. Soc. Sci. Vol. 6 (1), 216-222. 2012

N. Brown. What makes a good educator? The relevance of meta programmes. Assessment \& Evaluation in Higher Education, 29(5), 515-533. 2004

J. Carey, R. Churches, R., G. Hutchinson, G., T. Jones, J., P. Tosey, Neuro-linguistic programming and learning: teacher case studies on the impact of NLP in education. United Kingdom: CfBT Education Trust, dibentangkan dalam Education Show Seminar, 6 Mac 2010. 2010

Y.P. Chua, . Kaedah Penyelidikan Pendidikan: Buku 1. Kuala Lumpur: McGraw Hill. S.L. Kim and D. Ha, A JIT lot-splitting model for supply chain management: Enhancing buyer-supplier linkage, Int. J. Production Economics, vol. 86, pp. 1-10, 2003. 2006

E.L.Deci, R. Koestner, R., \& R. M. Ryan. A meta-analytic review of experiments examining the effects of extrinsic rewards on intrinsic motivation. Psychological Bulletin, 125(6), 627-668. 1999

A.E. Gottfried,. Academic intrinsic motivation in young elementary school children. Journal of Educational Psychology, 82(3), 525-538. 1990

F. Guay, J. Chanal, C.F. Ratelle, H.W. Marsh, S. Larose, \& M. Boivin. Intrinsic, identified, and controlled types of motivation for school subjects in young elementary school children. British Journal of Educational Psychology, 80 (4), 711-735. 2010

E. Kong. The Potential of Neuro-Linguistic Programming in Human Capital Development. The Electronic Journal of Knowledge Management. Volume 10 Issue 2 (pp 131-141), avalaible online at www.ejkm.com. 2012

E.R. Lai. Motivation: A Literature Review. Pearson. Research Report. Pearson's publications retrieved through http://www.pearsonassessments.com/research. 2011

J. Legall, J. Neuro Linguistic Programming: A Personnal Development Tool Applied to the Pedagogy and to the Improvement of Teachers/ Students Relation. Spain: Proceedings of the 5th WSEAS International Conference on Education Technology. Dec 15-16, 2006. 2011

M. Md. Taib,. NLP: Rahsia Sains dan Seni Kejayaan Diri. Kuala Lumpur: MTM Consultants Sdn. Bhd.2009

R. Millrood,. The role of NLP in teacher's classroom discourse. ELT Journals Volume, 58(1), 28-37. 2004

M. Z. Muhammad Kamil. Minat Dan Motivasi Pelajar Terhadap Mata Pelajaran Pendidikan Islam KBSM: Satu Tinjauan Ke Atas Pelajar-Pelajar Tingkatan 4 Di Sekolah Menengah Kebangsaan Tanjung Adang, Gelang Patah, Johor Bahru, Johor. Tidak diterbitkan. Tesis Sarjana Muda. Universiti Teknologi Malaysia, Skudai. 2001

M Shapiro. Successful Neuro-Linguistic Programming. United Kingdom: Cenveo Publisher Services. 2012

D.J. Stipek. Motivation and instruction. In D. C. Berliner \& R. C. Calfee (Eds.), Handbook of educational psychology. New York: Macmillan. pp. 85-113.1998

J.C.Turner. The influence of classroom contexts on young children's motivation for literacy. Reading Research Quarterly, 30(3), 410-441. 1995

P. Tosey, P, J. Mathison, \& D. Michelli, Mapping Transformative Learning: The Potential of Neuro-Linguistic Programming. Journal of Transformative Education, Vol. 3, No. 2, pp 140-167. 2005

J. Walter, \& A. Bayat,. Neurolinguistic Programming: verbal communication. British Medical Journal, 326, 7389, S83. 2003 
B.Weiner, History Of Motivational Research In Education. Journal Of Educational Psyhology. 82(4), 616622. 1990

A. Yahaya, A. \& A.H. Nurul, Teori-teori Motivasi. Johor: Fakulti Pendidikan, Universiti Teknologi Malaysia. 2010 